\title{
Persepsi Guru PAUD terhadap Pembelajaran Online: Fenomena Masa Pandemi Covid-19
}

\author{
Malpaleni Satriana ${ }^{1 凶}$, M. Ramli Buhari ${ }^{2}$, Makmun $^{3}$, Febry Maghfirah ${ }^{1}$, Wiwik Haryani ${ }^{1}$, Tri \\ Wahyuningsih $^{1}$, Hadi Wardana ${ }^{4}$, Antung Dewi Nurliana Sagita ${ }^{5}$, Lidia Oktamarina ${ }^{6}$, Ali Abu \\ Bakar $^{7}$ \\ Pendidikan Guru Pendidikan Anak Usia Dini, Univeristas Mulawarman, Samarinda ${ }^{1}$, Pendidikan \\ Jasmani, Universitas Mulawarman, Samarinda², Pendidikan Agama Islam, Universitas Mulawarman, \\ Samarinda ${ }^{3}$, Teknologi Pendidikan, Universitas Mulawarman, Samarinda4, Taman kanak-Kanak \\ Raudhatul Ilmi, Samarinda ${ }^{5}$, Pendidikan Islam Anak Usia Dini, Universitas Islam Negeri Raden Fatah, \\ Palembang6, Fiqh Modern, Universitas Islam Negeri Ar-Raniry, Banda Aceh ${ }^{7}$ \\ DOI: $10.31004 /$ obsesi.v6i1.1353
}

\begin{abstract}
Abstrak
Beberapa fenomena yang terjadi pada masa pandemi covid-19, diantaranya berkenaan pembelajaran online di lembaga PAUD. Penelitian bertujuan untuk mengungkap persepsi guru PAUD terhadap pembelajaran online. Partisipan 19 guru dari 18 lembaga PAUD di 9 provinsi Indonesia memberikan data hasil wawancara dan dokumentasi untuk diobservasi. Penelitian dilakukan selama 8 bulan (Agustus 2020-Maret 2021) yang menunjukkan bahwa pembelajaran online sebagai kegiatan pembelajaran yang dilakukan jarak jauh menggunakan perangkat teknologi; guru tetap menyiapkan perangkat pembelajaran, media, aplikasi, jadwal, dan strategi pada proses pembelajaran online; pembelajaran online tidak efektif diterapkan pada anak usia dini karena jaringan internet yang kurang stabil, anak kurang fokus memperhatikan guru, dan anak kurang tertarik pada pembelajaran online; orang tua memiliki peran penting dalam proses pembelajaran online. Kebaruan penelitian adalah mengkaji persepsi guru PAUD terhadap pembelajaran online walaupun belum mewakili persepsi guru PAUD di Indonesia dan diperoleh kelebihan dan kekurangan dari pembelajaran online pada anak usia dini.
\end{abstract}

Kata Kunci: persepsi; guru paud; anak usia dini; pembelajaran online; covid-19

\begin{abstract}
This article aims to reveal early childhood teachers' perceptions of online learning. Participants were 19 teachers from 18 early childhood education institutions in 9 provinces of Indonesia provided data from indirect interviews and documentation (photos and videos) for observation. Research conducted for 8 months (August 2020-March 2021) shows that online learning is a learning activity carried out remotely using technological devices, and in the process, the teacher prepares an implementation plan, media, applications, schedules, and learning strategies; The online learning process is not effective to be applied to early childhood because the internet network is less stable, children are less focused on paying attention to teachers, and children are less interested in online learning, therefore, parents have an important role in online learning process for children. The novelty of the research is to examine the perceptions of 19 early childhood teachers as participants in 9 provinces in Indonesia, from the perceptions of early childhood teachers, the advantages and disadvantages of online learning in early childhood are obtained.
\end{abstract}

Keywords: perception; early childhood teacher; early childhood; online learning; covid-19

Copyright (c) 2021 Malpaleni Satriana, M. Ramli Buhari, Makmun, Febry Maghfirah, Wiwik Haryani, Tri Wahyuningsih, Hadi Wardana, Antung Dewi NS, Lidia Oktamarina, Ali Abu Bakar

$\triangle$ Corresponding author:

Email Address : malpaleni@fkip.unmul.ac.id (Samarinda, Indonesia)

Received 7 May 2021, Accepted 22 May 2021, Published 29 May 2021

362 | Jurnal Obsesi: Jurnal Pendidikan Anak Usia Dini, 6(1), 2022 


\section{PENDAHULUAN}

The World Health Organization (WHO) menyatakan Corona Virus Disease 2019 (COVID19) sebagai darurat kesehatan masyarakat, dan dimulai tanggal 30 Januari 2020 menjadi perhatian internasional. Tanggal 11 Maret 2020, WHO menyebut COVID-19 sebagai pandemi (World Health Organization, 2020). Pandemi didefinisikan sebagai penyebaran penyakit baru di seluruh dunia (Morens et al., 2009). Peningkatan kasus COVID-19 menyebabkan dampak pada beberapa aspek, diantaranya aspek politik (Biscop, 2020), ekonomi (Carlsson-Szlezak et al., 2020), budaya (Flew \& Kirkwood, 2021), pertanian (Siche, 2020), kesejahteraan (Yang \& Ma, 2020), dan pendidikan (Onyema et al., 2020). Pada masa Pandemi COVID-19 pembelajaran online menjadi suatu keharusan yang tidak dapat dihindari agar proses pembelajaran tetap dapat dilaksanakan. Penyebaran COVID-19 telah menyebabkan penutupan institusi pendidikan di seluruh dunia. Data pada tanggal 21 Maret 2021 menunjukkan sebanyak 171.341 .667 pelajar di seluruh dunia, atau sekitar 9,8\% dari total pelajar di seluruh negara harus mengubah sistem pembelajaran karena COVID-19 (UNESCO, 2020). Selain itu, Pemerintah Republik Indonesia juga telah mengeluarkan Peraturan Pemerintah Republik Indonesia Nomor 21 Tahun 2020 mengenai Pembatasan Sosial Berskala Besar dalam Rangka Percepatan Penanganan COVID-19 yang di dalamnya terdapat peraturan bekerja dari rumah, ibadah di rumah, dan belajar dari rumah bagi siswa mulai dari jenjang pendidikan anak usia dini hingga pendidikan tinggi.

Belajar dari rumah dapat dilakukan melalui pembelajaran online. Pembelajaran online telah memberikan alternatif model pembelajaran dengan menyediakan aksesibilitas yang lebih baik bagi peserta didik yang sebelumnya kehilangan hak belajar (Conrad, 2002). Sangat penting untuk mengeksplorasi situasi dan masalah saat ini dengan pembelajaran online agar tetap dapat meningkatkan pengalaman dan pengetahuan siswa (Dumford \& Miller, 2018). Pada abad kedua puluh satu, pembelajaran online telah berkembang di seluruh dunia sebagai tempat untuk menghubungkan, mengkolaborasi, dan melibatkan pengguna dalam proses pembelajaran (Bhagat et al., 2016). Pembelajaran online sebagai konsep yang konsisten telah menjadi fokus penelitian pendidikan selama lebih dari dua dekade (Singh \& Thurman, 2019). Pembelajaran online untuk siswa dan guru adalah salah satu tren yang tumbuh paling cepat dalam penggunaan teknologi pendidikan (Means et al., 2012). Pembelajaran online saat ini terintegrasi dengan konektivitas jaringan sosial, yang membangun ekosistem untuk interaksi antara siswa, guru, dan profesor dari setiap penjuru dunia (Bhagat et al., 2016).

Pembelajaran online memiliki potensi untuk menjangkau khalayak yang lebih luas, dalam arti meluaskan ruang bermain bagi siswa yang kurang beruntung dalam akses ke pendidikan. Kebutuhan dan situasi unik dari para siswa dapat mempengaruhi pengalaman pendidikan mereka dan institusi harus berhati-hati agar tidak memperburuk kesenjangan yang ada (Dumford \& Miller, 2018). Keuntungan dari pembelajaran online adalah efektivitas dalam mendidik siswa, penggunaannya sebagai pengembangan profesional, efektivitas biaya untuk memerangi kenaikan biaya pendidikan dan menyediakan pendidikan kelas dunia untuk siapapun dengan aplikasi video dan audio secara langsung (Bartley \& Golek, 2004; De la Varre et al., 2010; Nguyen, 2015).

Guru sebagai pelaksana dalam pembelajaran online harus mampu mengkondisikan seluruh komponen pembelajaran. Hal tersebut meliputi metode pembelajaran, media yang akan digunakan dalam pembelajaran, penggunaan waktu pembelajaran yang berkaitan dengan waktu penggunaan aplikasi, serta faktor psikologis dan sosial yang secara signifikan mempengaruhi motivasi guru saat mengajar. Guru memiliki tugas dan tanggung jawab yang tidak mudah saat harus mengalihkan sistem pembelajaran tatap muka menjadi sistem pembelaran online dikarenakan belum adanya pengalaman belajar online guru dan siswa sebelumnya. Seorang guru harus mengatasi semua permasalahan yang terjadi dalam pembelajaran online secara responsif agar pembelajaran terus dapat dilaksanakan dan anak tetap mendapatkan pengalaman belajar. Namun, untuk meningkatkan keterlibatan aktif guru 
dan penyampaian pembelajaran yang bermakna dalam pembelajaran online, persepsi guru terhadap pembelajaran online juga perlu untuk dikaji.

Pengertian dari persepsi adalah kemampuan manusia dalam membedakan, mengelompokkan kemudian memfokuskan pikiran kepada suatu hal dan untuk menginterpretasikannya. Persepsi adalah sebuah proses top-down, dimana otak mengorganisir informasi dan membawanya dalam sebuah konteks yang selanjutnya akan menghasilkan cara pandang manusia terhadap sesuatu sebagai interpretasi individual dan atau yang dapat dipahami bersama secara sosial dan budaya (Alizamar, 2013). Persepsi adalah proses yang dijalankan otak untuk menafsirkan informasi sensorik, mengubahnya menjadi gambaran berarti perihal dunia (Nevid, 2017). Melalui persepsi, otak berusaha mengartikan kumpulan rangsangan sensorik yang menimpa organ sensorik. Persepsi adalah proses aktif dimana otak menyusun berbagai potongan informasi sensorik sehingga membentuk kesan atau gambar teratur perihal dunia. Persepsi adalah proses kognitif yang memungkinkan kita untuk menginterpretasikan dan memahami lingkungan sekitar (Kreitner, R., \& Kinicki, 2014).

Persepsi individu dipengaruhi oleh faktor fungsional dan faktor struktural (Couto, 2016). Faktor fungsional ialah faktor-faktor yang bersifat personal. Misalnya, kebutuhan individu, usia, pengalaman masa lalu, kepribadian, jenis kelamin, emosi, dan hal-hal lain yang bersifat subjektif. Faktor struktural adalah faktor di luar individu, misalnya lingkungan, budaya, dan norma sosial sangat berpengaruh terhadap seseorang dalam mempersepsikan sesuatu. Ahli lain menyatakan beberapa faktor yang dapat membentuk dan mendistoris persepsi, diantaranya faktor-faktor pendahulu sebelumnya (preceiver), faktor-faktor pada situasi (situation), faktor-faktor pada target (target) (Robbins, S., \& Timothy, 2014). Rakhmat menyatakan faktor-faktor fungsional yang menentukan persepsi seseorang berasal dari kebutuhan, pengalaman masa lalu dan hal-hal lain termasuk yang kita sebut sebagai faktorfaktor personal. Selanjutnya Rakhmat menjelaskan yang menentukan persepsi bukan jenis atau bentuk stimulus, tetapi karakteristik orang yang memberi respon terhadap stimulus (Adri, 2019).

Beberapa tahun terakhir, terdapat beberapa penelitian yang mengkaji perihal persepsi guru terhadap pembelajaran online. Peneliti dari Pakistan (Mukhtar et al., 2020) melaporkan persepsi guru dan siswa mengenai kelebihan, keterbatasan pembelajaran online dan hasil penilitian tersebut menunjukkan keunggulan dari pembelajaran online antara lain adalah pembelajaran dilakukan jarak jauh, kenyamanan, aksesibilitas, sedangkan keterbatasan melibatkan ketidak efisienan dan kesulitan dalam menjaga integritas akademik. Peneliti lainnya (Rasmitadila et al., 2020) melakukan penelitian studi kasus di Indonesia perihal persepsi guru sekolah dasar terhadap pembelajaran online selama periode pandemi COVID19, dan hasilnya menunjukkan bahwa secara garis besar keberhasilan pembelajaran online di Indonesia pada masa pandemi COVID-19 ditentukan oleh kesiapan teknologi yang sejalan dengan kurikulum humanistik nasional, dukungan dan kerjasama dari seluruh pemangku kepentingan, baik pemerintah, sekolah, guru, orang tua maupun masyarakat.

Selain persepsi guru sekolah dasar terhadap pembelajaran online, belum terdapat penelitian yang mengkaji perihal persepsi guru Pendidikan Anak Usia Dini (PAUD) terhadap pembelajaran online. Pembelajaran online merupakan hal baru bagi guru PAUD, sehingga persepsi guru PAUD terhadap pembelajaran online merupakan suatu hal penting yang perlu untuk dikaji lebih dalam. Hal ini diperlukan agar dapat diketahui apa saja yang menjadi kelebihan dan kekurangan pembelajaran online di lembaga PAUD dari persepsi guru PAUD, sehingga menjadi masukan untuk berbagai pihak yang berkepentingan demi kemajuan lembaga PAUD.

Oleh karena itu, studi ini melakukan penelitian untuk mengungkap makna konsep atau persepsi guru pendidikan anak usia dini (PAUD) terhadap pembelajaran online yang didasari oleh kesadaran yang terjadi pada masa pandemi COVID-19 di Indonesia. Kesiapan pembelajaran online tidak hanya diperlukan pada saat pandemi saja, akan tetapi juga untuk kesiapan pendidikan era revolusi industri 4.0 di Indonesia, dimana pendidikan harus mampu 
membuka jendela dunia melalui genggaman, contohnya dalam memanfaatkan Internet of Things (IOT) di lembaga PAUD.

\section{METODE PENELITIAN}

Penelitian menggunakan metode kualitatif dengan pendekatan fenomenologi karena pendekatan ini melihat pengalaman manusia melalui deskripsi dari orang yang menjadi partisipan penelitian, sehingga peneliti dapat memahami pengalaman hidup partisipan (Creswell, 1994). Pada penelitian ini, pendekatan fenomenologi dilakukan untuk mengkaji persepsi guru PAUD terhadap pembelajaran online selama masa pandemi COVID-19 di lembaga PAUD Indonesia, dengan pendekatan secara mendalam yang dilakukan selama 8 bulan secara bertahap untuk melihat progress pembelajaran online di lembaga PAUD (Agustus tahun 2020 sampai dengan Maret tahun 2021).

Partisipan dalam penelitian ini terdiri dari 19 guru PAUD dan belum menggambarkan persepsi guru PAUD Indonesia terhadap pembelajaran online secara keseluruhan, karena baru mewakili 18 lembaga PAUD dari 9 provinsi Indonesia diantaranya provinsi Lampung, Bengkulu, Sumatera Selatan, Jawa Tengah, Jawa Timur, Sulawesi Selatan, Sulawesi Barat, Kalimantan Timur, dan Kalimantan Barat. Partisipan dipilih menggunakan purposeful sampling, dimana sampel dipilih tergantung dengan tujuan penelitian tanpa memperhatikan kemampuan generalisasinya (Patton, 1990) dan tidak ada aturan yang baku tentang jumlah minimal dari partisipan (Patton, 1990). Kesamaan dari partisipan yang dipilih diantaranya berusia 29-30 tahun, memiliki gelar sarjana pendidikan PAUD, telah mengajar di lembaga paud antara 5-7 tahun, mengajar di lembaga PAUD swasta, memiliki kemampuan yang baik dalam menggunakan beberapa aplikasi pembelajaran online, memiliki kemampuan yang cukup baik dalam merancang pembelajaran online atau memanfaatkan video pembelajaran.

Guna mencapai triangulasi data, peneliti mengumpulkan data menggunakan observasi dari dokumentasi yang dikirimkan guru berupa foto dan video serta wawancara tidak langsung secara mendalam terhadap 19 guru PAUD dari 18 lembaga PAUD yang tersebar di 9 provinsi Indonesia. Semua wawancara dilakukan dalam bahasa Indonesia menggunakan aplikasi dengan pemberitahuan sebelumnya dan persetujuan dari para partisipan.

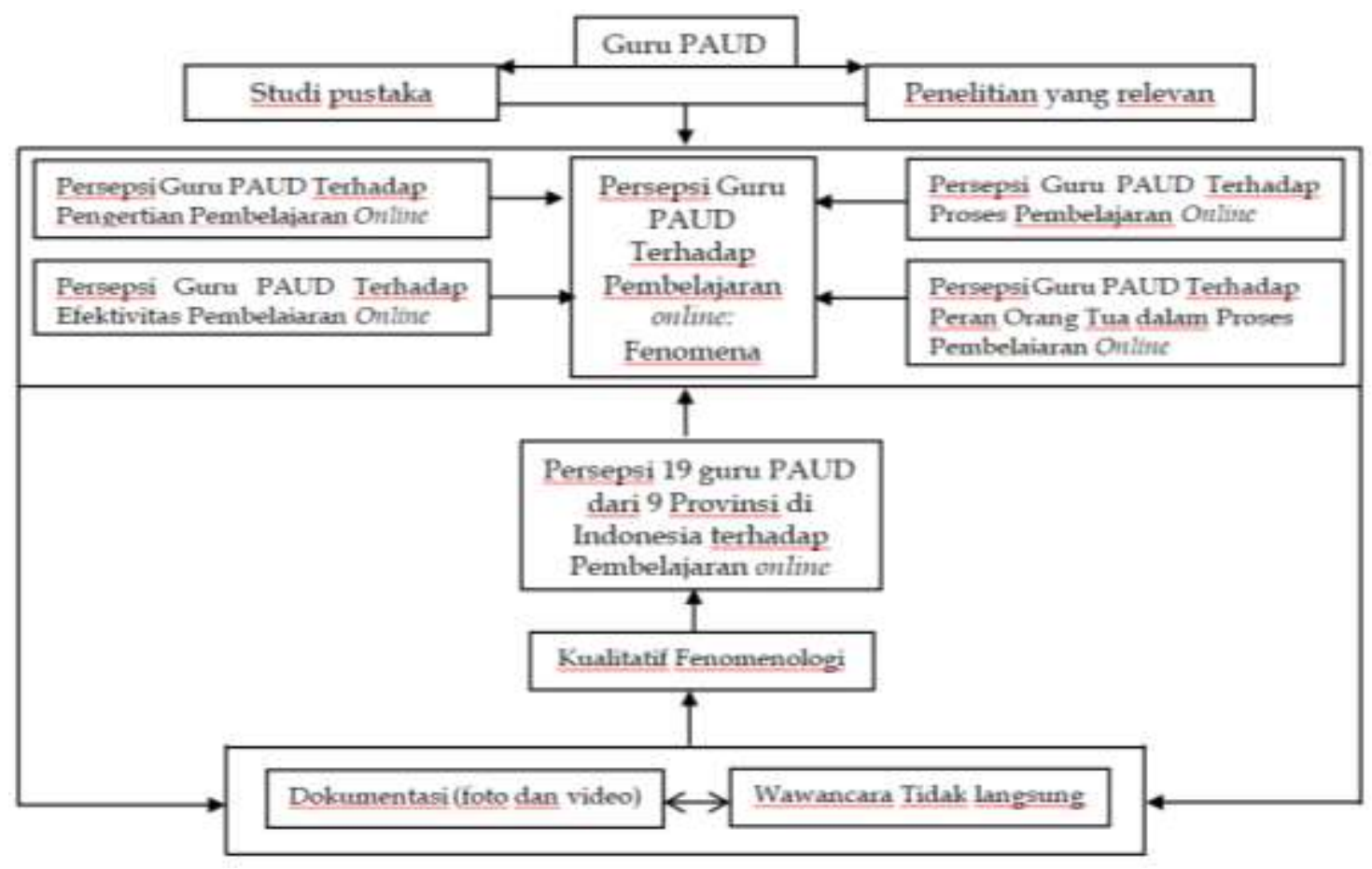

Gambar 1. Alur Penelitian Persepsi Guru PAUD Terhadap Pembelajaran Online: Fenomena Masa Pandemi Covid-19 
Transkrip wawancara tidak langsung dianalisis menggunakan pengkodean terbuka dan pengkodean aksial (Corbin \& Strauss, 2014). Konsisten dengan pedoman untuk analisis data kualitatif, berikut prosedur yang dilakukan (Widodo, 2014): pertama, menyiapkan template (desain/format transkrip): Peneliti harus menyiapkan template berisi beberapa fitur transkrip. Peneliti dapat mendesain template berdasarkan susunan data, penyimpanan data serta pengambilan data. Kedua, mengelola informasi (manajemen data atau penyusunan): Setelah peneliti mendesain template, peneliti melanjutkan untuk meletakkan dan mengelola data dalam transkrip template. Penomoran baris dialog adalah cara untuk melihat lebih dekat pada data tertentu seandainya ada banyak data dalam transkrip. Ketiga, Memperlakukan data yang ditranskripsikan (tata bahasa data): Data wawancara terjadi secara alami informasinya harus disajikan dengan cara yang memadai secara interaksional. Data harus diberi notasi atau simbol lisan (misalnya, intonasi, penanda ragu-ragu, pembicaraan terpotong). Simbol-simbol ini menunjukkan sifat ujaran percakapan dan menunjukkan perbedaan antara wacana lisan dan wacana tertulis. Keempat, Menempatkan data yang ditranskrip secara etis (letak etis): Aktor yang terlibat dalam wawancara harus dirahasiakan kecuali mereka menginginkan nama mereka yang dirahasiakan diidentifikasi tertulis dalam formulir persetujuan. Peneliti harus komunikasikan masalah ini kepada partisipannya untuk menghindari konflik etika. Tingkat kerahasiaan dan anonimitas bervariasi sesuai konteks sosio-kelembagaan hingga lainnya.

\section{HASIL DAN PEMBAHASAN}

Hasil analisis data wawancara dengan 19 guru PAUD sebagai partisipan dalam penelitian ini menunjukkan bahwa semua guru telah mengetahui apa yang dimaksud pembelajaran online, walaupun semua partisipan belum pernah menerapkan pembelajaran online sebelumnya di lembaga PAUD, akan tetapi dikarenakan situasi pandemi COVID-19 dan terdapat peraturan dari pemerintah untuk belajar dari rumah, hal tersebut membuat guru diharuskan untuk menerapkan pembelajaran online agar proses pembelajaran di lembaga PAUD tetap dapat dilaksanakan.

\section{Persepsi Guru PAUD Terhadap Pengertian Pembelajaran Online}

Partisipan dari 19 guru PAUD memiliki beragam persepsi terkait pengertian dari pembelajaran online, akan tetapi semua partisipan setuju bahwa pembelajaran online dianggap sebagai kegiatan pembelajaran yang dilakukan secara jarak jauh dengan menggunakan perangkat teknologi seperti handhone, komputer, dan laptop dan didukung juga dengan jaringan internet, seperti yang dikatakan dalam wawancara berikut:

Pembelajaran yang dilakukan oleh guru dan murid tanpa bertemu tetapi dengan menggunakan perangkat teknologi seperti handphone (p.3).

Pembelajaran yang dilakukan secara tidak langsung atau tanpa tatap muka, dengan perantara jaringan internet ( $p .7)$.

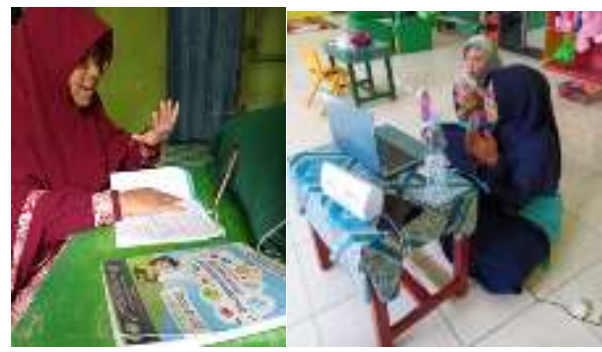

Gambar 2. Persepsi Guru PAUD terhadap Pengertian Pembelajaran Online 
Pernyataan ini juga didukung oleh partisipan lain yang menjelaskan bahwa dalam melaksanakan pembelajaran online, tidak hanya membutuhkan jaringan internet dan perangkat terknologi, akan tetapi dibutuhkan juga aplikasi yang dapat membantu pelaksaan pembelajaran online tersebut:

Pembelajaran online adalah pembelajaran yang dilaksanakan secara online (tidak tatap muka) dengan menggunakan beberapa aplikasi pembelajaran dan jejaring sosial (p.4).

Adapun partisipan lain yang menyebutkan aplikasi-aplikasi yang dapat digunakan dalam melaksanakan pembelajaran online, dan menyampaikan bahwa yang memandu proses pembelajaran online adalah guru, hanya saja anak juga perlu didampingi oleh orang tua atau orang dewasa lainnya dalam menggunakan aplikasi tersebut.

Proses pembelajaran jarak jauh dapat menggunakan aplikasi youtube, google classroom, dan zoom. Proses pembelajaran tersebut dipandu oleh guru dan anak didampingi orang tua di rumah (p.8).

Pembelajaran secara online sering juga disebut dengan pembelajaran daring (dalam jaringan), sedangkan pembelajaran secara tatap muka disebut dengan pembelajaran luring (luar jaringan), seperti jawaban wawancara partisipan berikut:

Pembelajaran dilakukan dengan perantara dunia maya dengan menggunakan internet atau tepatnya di sebut belajar dalam jaringan ( $p .1)$.

Tampak jelas bahwa pembelajaran online dapat terlaksana dengan baik jika didukung dengan jaringan internet yang stabil, perangkat teknologi yang memadai, serta pendampingan dari orang tua di rumah dalam membantu anak menggunakan perangkat teknologi tersebut. Pembelajaran online berakar pada tradisi pendidikan jarak jauh (Means et al., 2012). Pembelajaran online dijelaskan oleh sebagian besar penulis sebagai akses ke pengalaman belajar melalui penggunaan beberapa teknologi (Benson, 2002; Conrad, 2002; Moore et al., 2011). Pembelajaran online secara luas didefinisikan sebagai penggunaan internet dalam beberapa cara untuk meningkatkan interaksi antara guru dan siswa. Pembelajaran online mencakup bentuk interaksi asinkron seperti alat penilaian dan penyediaan materi kursus berbasis web dan interaksi sinkron melalui email, grup berita, dan alat konferensi, seperti grup obrolan. Ini mencakup instruksi berbasis kelas dan juga mode pendidikan jarak jauh. Istilah lain yang identik dengan pembelajaran online adalah pendidikan berbasis web dan pembelajaran elektronik (Curtain, 2002).

Pembelajaran online juga digunakan dalam banyak kasus sebagai sinonim dari pendidikan jarak jauh karena kebanyakan pendidikan jarak jauh saat ini dilakukan secara online (Scagnoli, 2009). Pendidikan online atau e-Learning secara umum didefinisikan sebagai jembatan ruang antara guru dan siswa melalui penggunaan teknologi berbasis web (Lee, 2017; Moore et al., 2011; Ryan et al., 2016). Pembelajaran online (yang juga disebut e-learning, pembelajaran digital, atau pembelajaran berbasis komputer) dapat didefinisikan sebagai instruksi yang disampaikan pada perangkat digital yang dimaksudkan untuk mendukung pembelajaran (Clark \& Mayer, 2012). Howlett mendefinisikan pembelajaran online sebagai penggunaan teknologi dan media elektronik untuk menyampaikan, mendukung, dan meningkatkan pembelajaran dan pengajaran dan melibatkan komunikasi antara pelajar dan guru menggunakan konten online (Howlett et al., 2009).

\section{Persepsi Guru PAUD terhadap Proses Pembelajaran Online}

Terdapat berbagai macam proses pembelajaran online yang telah diterapkan di PAUD. Guru tetap menyiapkan rencana pelaksanaan pembelajaran, media pembelajaran, aplikasi pembelajaran, jadwal pembelajaran, dan strategi pembelajaran agar pelaksanaan proses pembelajaran dapat terlaksana dengan lancar dan efektif, seperti yang dikatakan dalam 
wawancara berikut:

Pada pembelajaran online, guru tetap menyiapkan rencana pelaksanaan pembelajaran mingguan $(R P P M)$ dan rencana pelaksanaan pembelajaran harian (RPPH), selain itu guru juga meyiapkan media elektronik seperti handphone dan laptop sebagai perangkat untuk melaksanakan pembelajaran online (p.9)

Guru membuat rencana kegiatan, materi pembelajaran, bahan ajar dan video pembelajaran untuk digunakan dalam proses pembelajaran online (p.11).
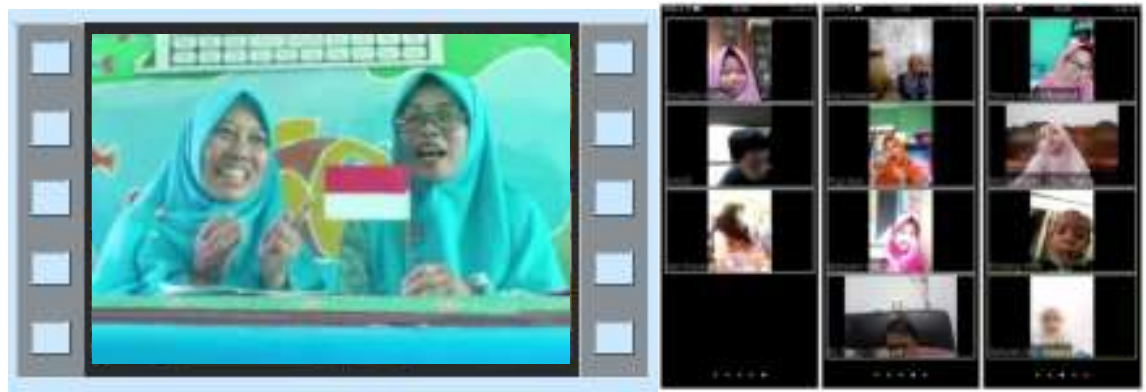

\section{Gambar 3. Proses Pembelajaran Online}

Pernyataan tersebut juga didukung oleh pernyataan partisipan lain yang menyatakan bahwa dalam melaksanakan pembelajaran online perlu untuk menyiapkan RPPM dan RPPH serta aplikasi yang dapat digunakan untuk melaksanakan pembelajaran online.

Mendukung proses pembelajaran online, guru membuat grup kelas di aplikasi whatsapp dan telegram, dan guru mengirimkan RPPM dan RPPM melalui aplikasi tersebut (p.2)

Adapun aplikasi lain yang digunakan partisipan dalam mendukung proses pembelajaran onlinenya.

Proses pembelajaran online menggunakan youtube dan google classroom yang dipandu oleh guru dan anak didampingi orang tua di rumah (p.8).

Selain mempersiapkan rencana pelaksanaan pembelajaran, media pembelajaran, dan aplikasi pembelajaran. Guru juga menyiapkan jadwal pembelajaran dan strategi pembelajaran.

Agar proses pembelajaran online berjalan dengan lancar, selain menyiapkan rencana pelaksanaan pembelajaran, media pembelajaran, dan aplikasi pembelajaran. Guru juga perlu mengatur jadwal pembelajaran agar pelaksanaan proses pembelajaran dapat berjalan dengan lancar (p.4).

Pelaksanaan pembelajaran online perlu disiapkan rencana pelaksanaan pembelajaran, media pembelajaran, aplikasi pembelajaran, jadwal pembelajaran, dan strategi pembelajaran agar pelaksanaan proses pembelajaran dapat terlaksana dengan lancar dan efektif. Hal tersebut didukung oleh pernyataan ahli yang menyatakan bahwa dalam menyelenggarakan pembelajaran online, beberapa aspek yang perlu diperhatikan adalah perencanaan, pengukuran kebutuhan siswa, sistem pendukung, pengembangan kompetensi guru, perancangan materi, pemilihan platform yang tepat, dan evaluasi kemajuan hasil pembelajaran (Lang, 2004). Ahli lain melaporkan aspek yang perlu diperhatikan dalam pembelajaran online adalah siswa, guru, materi pembelajaran yang meliputi kualitas dan fleksibilitas, kualitas teknologi atau platform yang digunakan, dan lingkungan belajar (Inoue, 2007). Pendapat lain menyebutkan perlunya tiga aspek utama yaitu pengembang, pendidik, dan siswa yang masing-masingnya menghadapi tantangan yang sama yaitu tantangan teknologi, tantangan pembangunan, dan tantangan pedagogis (Muhdi et al., 2020). 
DOI: $10.31004 /$ obsesi.v6i1.1353

\section{Persepsi Guru PAUD Terhadap Efektivitas Pembelajaran Online}

Semua partisipan berpendapat bahwa proses pembelajaran online kurang efektif untuk diterapkan pada anak usia dini disebabkan oleh beberapa alasan diantaranya jaringan internet yang kurang stabil, anak kurang fokus dalam memperhatikan guru, anak kurang tertarik pada pembelajaran secara online dan anak membutuhkan perhatian langsung saat proses pembelajaran, sementara pada saat pembelajaran online, guru tidak dapat memberikan perhatian secara langsung kepada anak, seperti yang dikatakan dalam wawancara berikut:

Pembelajaran online tidak seefektif kegiatan pembelajaran tatap muka, salah satunya disebabkan oleh jaringan internet yang kurang stabil sehingga menyebabkan proses pembelajaran online terkadang terputus secara tiba-tiba dan terkadang bahkan tidak tersambung sama sekali (p.2).
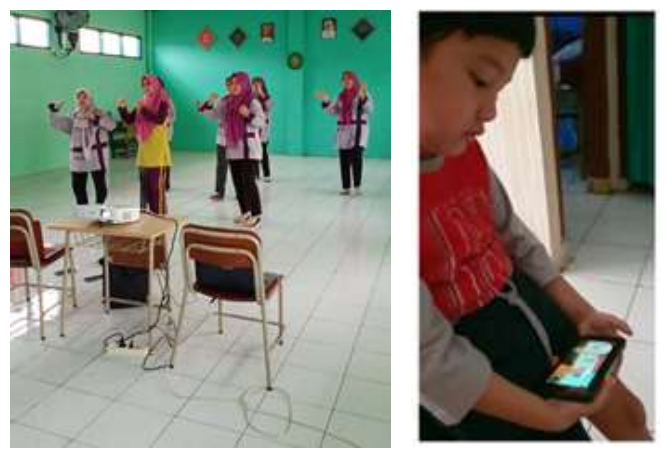

\section{Gambar 4. Efektivitas Pembelajaran Online}

Selain disebabkan oleh jaringan internet yang kurang stabil, pembelajaran online dianggap kurang efektif karena anak kurang fokus dalam mengikuti pembelajaran online.

Pembelajaran online sekiranya kurang efektif untuk diterapkan pada anak usia dini, karena anak menjadi kurang fokus dalam memperhatikan guru (p.6).

Pernyataan ini juga didukung oleh partisipan lain yang menjelaskan bahwa terdapat Beberapa anak yang kurang tertarik dalam mengikuti pembelajaran online.

Kurang efektif, karena ada beberapa anak yang kurang tertarik apalagi pada saat kegiatan pembelajaran menggunakan salah satu aplikasi yang digunakan untuk pembelajaran online (p.14).

Guru juga mengungkapkan salah satu alasan kurang efektifnya pembelajaran online dikarenakan guru tidak dapat memberikan perhatian langsung pada anak pada saat proses pembelajaran.

Pembelajaran online tidak efektif karena anak usia dini membutuhkan perhatian langsung pada saat belajar, sementara pada saat pembelajaran online, guru tidak bisa memberikan perhatian secara langsung kepada anak (p.8).

Kurang efektifnya pembelajaran online untuk diterapkan pada anak usia dini disebabkan oleh beberapa alasan diantaranya jaringan internet yang kurang stabil, anak kurang fokus dalam memperhatikan guru, anak kurang tertarik pada pembelajaran secara online dan anak membutuhkan perhatian langsung saat proses pembelajaran, sementara pada saat pembelajaran online, guru tidak dapat memberikan perhatian secara langsung kepada anak. Hal tersebut di perkuat oleh pernyataan Muilenburg dan Berge (2005) yang melaporkan delapan faktor yang ditemukan dapat menghambat anak dalam pembelajaran online, diantaranya (a) masalah administrasi, (b) interaksi sosial, (c) keterampilan akademik, (d) keterampilan teknis, (e) motivasi pelajar, (f) waktu dan dukungan untuk studi, (g) biaya dan akses ke Internet, dan (h) masalah teknis. Penelitian Sahoo (2020) melaporkan persentase yang 
signifikan dari siswa dan guru ditemukan merasa stres terisolasi dan kurang percaya diri dalam platform pembelajaran online dan tidak setuju bahwa kurikulum dapat secara efektif jika disampaikan melalui mode online. Tetapi mayoritas siswa dan guru menerima pembelajaran online sebagai pilihan yang lebih baik untuk belajar selama pandemi COVID-19 ini tetapi tidak setuju sebagai alternatif dari pendekatan pembelajaran tatap muka, jika permasalahan yang ditemukan pada pembelajaran online tidak diberikan solusi atau tidak diatasi oleh pihak yang berkepentingan.

\section{Persepsi Guru PAUD Terhadap Peran Orang Tua dalam Proses Pembelajaran Online}

Semua partisipan setuju jika orang tua anak memiliki peran penting dalam proses pembelajaran online bagi anak. Anak usia dini membutuhkan orang tua dalam menggunakan perangkat teknologi agar dapat mengikuti pembelajaran online. Partisipan 19 guru PAUD partisipan dalam penelitian ini sependapat bahwa peran orang tua sangat penting dalam mendampingi anak selama pelaksanaan pembelajaran online, memberikan bimbingan dalam penggunaan aplikasi, perhatian dan motivasi kepada anak agar anak tetap konsisten dan semangat dalam pembelajaran online, seperti yang dikatakan dalam wawancara berikut:

Orangtua sangat memiliki peran dalam pembelajaran online, karena orangtua yang terdekat dengan anak dan paham akan kondisi anak di rumah dan orang tua yang akan mendampingi anak dalam upaya stimulasi tumbuh kembang anak (p.1).

Orang tua memiliki peran penting dalam penerapan pembelajaran online, karena anak memerlukan pendampingan saat anak belajar sehingga anak dapat memahami materi yang diberikan (p.2).

Tanpa adanya orangtua yang mendampingi hanya segelintir anak yang bisa mandiri mengikuti kegiatan dalam jaringan (daring) dan sebagian besar lainnya masih butuh bantuan orangtua dalam mendampingi (p.7)

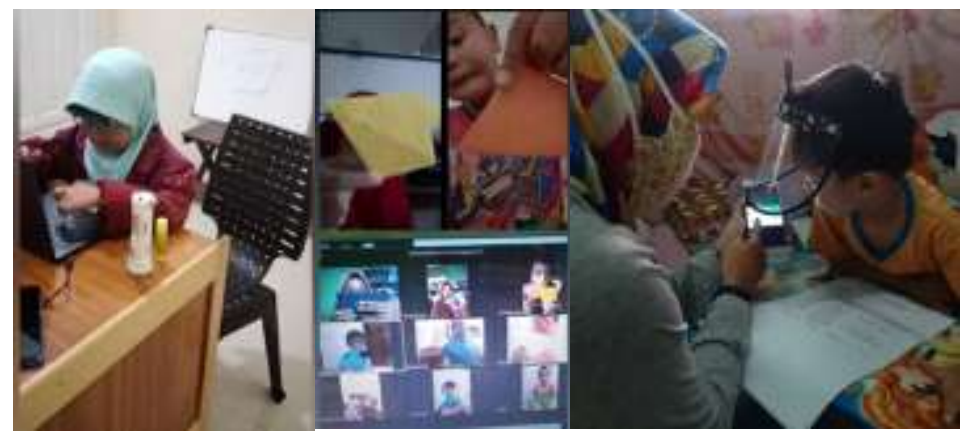

\section{Gambar 5. Peran Orang Tua dalam Proses Pembelajaran Online}

Selain mendampingi, peran orang tua juga sangat penting untuk memberikan bimbingan dan perhatian kepada anak selama pembelajaran online, agar penggunaan teknologi yang digunakan tidak memberikan dampak buruk pada anak.

Peran orangtua sangat penting karena di usia anak yang masih muda dalam hal ini usia kelompok bermain dan usia taman kanak-kanak, masih sangat perlu mendapatkan bimbingan dan perhatian. Selama pembelajaran online ini, sosok yang paling sangat membantu dalam peningkatan kemampuan anak adalah orangtua. Orangtua yang selalu berada di dekat anak dan dapat memberikan contoh langsung kepada anak (p.4).

Selama mendampingi anak, orang tua juga dapat memberikan motivasi kepada anak agar tetap konsisten dan semangat untuk melakukan pembelajaran online.

Peran orang tua sangat penting dalam pembelajaraan online dengan memberi motivasi kepada anak agar anak tetap konsisten dan semangat dalam pembelajaran online ( $p .10)$ 
Orang tua memiliki peran penting untuk mendampingi anak selama mengikuti pembelajaran online. Peran orang tua sangat penting untuk berbagai aspek perkembangan anak. Otto (2015) menyatakan bahwa keterlibatan orang tua dalam bimbingan dan pendidikan anak sangat diperlukan. Orang tua memainkan peran penting dalam perkembangan bahasa anak. Berk (2013) menyatakan bahwa peran orang tua memprediksi skor bahasa dan IQ yang lebih baik pada anak usia dini. Peran orang tua yang dapat diberikan kepada anak menurut Susanto (Susanto, 2017) di antaranya, melatih, membiasakan diri berperilaku sesuai dengan nilai-nilai berdasarkan acuan moral, dan perlu adanya kontrol orang tua untuk mengembangkannya. Seefeldt (2010) menyatakan bahwa peran orang tua sangat membantu dalam studi sosial, karena semua jenis keterlibatan, informal dan formal, menyatukan orang tua, guru, dan anak-anak berfungsi sebagai sumber daya untuk pembelajaran dan pembelajaran sosial, dan menghubungkan studi sosial dengan dunia anak.

\section{SIMPULAN}

Pembelajaran online sebagai kegiatan pembelajaran yang dilakukan secara jarak jauh menggunakan perangkat teknologi juga dilaksanakan di lembaga PAUD. Pembelajaran online di lembaga PAUD juga tetap menyiapkan rencana pelaksanaan pembelajaran, media, aplikasi, jadwal, dan strategi pembelajaran agar pelaksanaan pembelajaran dapat terlaksana dengan lancar dan efektif. Pembelajaran online tidak efektif untuk diterapkan pada anak usia dini karena jaringan internet yang kurang stabil, anak tidak fokus saat memperhatikan guru hanya di layar aplikasi, anak tidak terlalu tertarik pada pembelajaran secara online karena anak membutuhkan perhatian langsung saat proses pembelajaran, sementara pada saat pembelajaran online, guru tidak dapat memberikan perhatian secara langsung kepada anak.

\section{UCAPAN TERIMA KASIH}

Ucapan terima kasih ditujukan kepada para partisipan yang terlibat dalam penelitian ini, reviewer yang telah memberikan masukan berharga serta editor Jurnal Obsesi yang telah memfasilitasi penerbitan artikel ini.

\section{DAFTAR PUSTAKA}

Adri, J. (2019). Persepsi orang tua terhadap pentingnya pendidikan anak di desa taduasa kecamatan batuatas kabupaten buton selatan. Jurnal Akademik Pendidikan Ekonomi, $6(1)$.

Alizamar, N. C. (2013). Psikologi Persepsi \& Desain Informasi. A Psicanalise Dos Contos de Fadas. Tradução Arlene Caetano, 466.

Bartley, S. J., \& Golek, J. H. (2004). Evaluating the cost effectiveness of online and face-to-face instruction. In Educational Technology and Society (Vol. 7, Issue 4, pp. 167-175). JSTOR.

Benson, A. D. (2002). Using Online Learning To Meet Workforce Demand: A Case Study of Stakeholder Influence. Quarterly Review of Distance Education, 3(4), 443-452.

Berk, L. E. (2013). Child Development: History theory and applied directions. USA: Pearson Education Inc.

Bhagat, K. K., Wu, L. Y., \& Chang, C. Y. (2016). Development and validation of the perception of students towards online learning (POSTOL). Educational Technology and Society, 19(1), 350-359. https:// doi.org/10.1037/t64255-000

Biscop, S. (2020). Coronavirus and Power: The Impact on International Politics. Security Policy Brief - Egmont Institute - The Royal Institute for International Relations, 126, 4. http://www.egmontinstitute.be/content/uploads/2020/03/SPB126-sven-corona260320.pdf?type $=$ pdf

Carlsson-Szlezak, P., Reeves, M., \& Swartz, P. (2020). What coronavirus could mean for the global economy. Harvard Business Review, 3(March), 10. http://www.amcham- 
egypt.org/bic/pdf/corona1/What Coronavirus Could Mean for the Global Economy by HBR.pdf\%0Ahttps://hbr.org/2020/03/what-coronavirus-could-mean-for-theglobal-economy

Clark, R. C., \& Mayer, R. E. (2012). e-Learning and the Science of Instruction: Proven Guidelines for Consumers and Designers of Multimedia Learning: Third Edition. In eLearning and the Science of Instruction: Proven Guidelines for Consumers and Designers of Multimedia Learning: Third Edition. john Wiley \& sons. https://doi.org/10.1002/9781118255971

Conrad, D. (2002). Deep in the Hearts of Learners: Insights into the Nature of Online Community. Journal of Distance Education, 17(1), 1-19.

Corbin, J., \& Strauss, A. (2014). Basics of qualitative research: Techniques and procedures for developing grounded theory. Sage publications.

Creswell, J. W. (1994). Research Design: Quantitative And Qualitative Approach. Sage publications.

Curtain, R. (2002). Online delivery in vocational education and training sector: Improving cost effectiveness. In Online. National Centre for Vocational Education Research. https:// doi.org/Report

De la Varre, C., Keane, J., \& Irvin, M. J. (2010). Enhancing online distance education in small rural US schools: A hybrid, learner-centred model. Australasian Journal of Educational Technology, 26(8), 193-205. https://doi.org/10.14742/ajet.1019

Dumford, A. D., \& Miller, A. L. (2018). Online learning in higher education: exploring advantages and disadvantages for engagement. Journal of Computing in Higher Education, 30(3), 452-465. https:// doi.org/10.1007/s12528-018-9179-z

Flew, T., \& Kirkwood, K. (2021). The impact of COVID-19 on cultural tourism: art, culture and communication in four regional sites of Queensland, Australia. Media International Australia, 178(1), 16-20. https:/ / doi.org/10.1177/1329878X20952529

Howlett, D., Vincent, T., Gainsborough, N., Fairclough, J., Taylor, N., Cohen, J., \& Vincent, R. (2009). Integration of a case-based online module into an undergraduate curriculum: What is involved and is it effective? E-Learning, 6(4), 372-384. https:// doi.org/10.2304/elea.2009.6.4.372

Inoue, Y. (2007). Online education for lifelong learning. In Online Education for Lifelong Learning. IGI Global. https:// doi.org/10.4018/978-1-59904-319-7

Kreitner, R., \& Kinicki, A. (2014). Perilaku organisasi (terjemahan). Salemba Empat.

Lang, M. (2004). The Online Educator. A Guide to Creating the Virtual Classroom, M. McVay Lynch. Education and Information Technologies, 9(1), 91-93. https:// doi.org/10.1023/B:EAIT.0000024308.72932.91

Lee, K. (2017). Rethinking the accessibility of online higher education: A historical review. Internet and Higher Education, 33, 15-23. https:// doi.org/10.1016/j.iheduc.2017.01.001

Means, B., Toyama, Y., Murphy, R., Bakia, M., \& Jones, K. (2012). Evaluation of evidence-based practices in online learning: A meta-analysis and review of online learning studies. In Learning Unbound: Select Research and Analyses of Distance Education and Online Learning (pp. 41-133). Centre for Learning Technology.

Mohalik, R., \& Sahoo, S. (2020). E-Readiness and Perception of Student Teachers' Towards Online Learning in the Midst of COVID-19 Pandemic. SSRN Electronic Journal. https://doi.org/10.2139/ssrn.3666914

Moore, J. L., Dickson-Deane, C., \& Galyen, K. (2011). E-Learning, online learning, and distance learning environments: Are they the same? Internet and Higher Education, 14(2), 129135. https://doi.org/10.1016/j.iheduc.2010.10.001

Morens, D. M., Folkers, G. K., \& Fauci, A. S. (2009). What is a pandemic? The University of Chicago Press. https:// doi.org/10.1086/644537 
Muhdi, Nurkolis, \& Yuliejantiningsih, Y. (2020). The Implementation of Online Learning in Early Childhood Education During the Covid-19 Pandemic. JPUD - Jurnal Pendidikan Usia Dini, 14(2), 247-261. https:// doi.org/10.21009/JPUD.142.04

Muilenburg, L. Y., \& Berge, Z. L. (2005). Students Barriers to Online Learning: A factor analytic study. In Distance Education (Vol. 26, Issue 1, pp. 29-48). Taylor \& Francis. https://doi.org/10.1080/01587910500081269

Mukhtar, K., Javed, K., Arooj, M., \& Sethi, A. (2020). Advantages, limitations and recommendations for online learning during covid-19 pandemic era. Pakistan Journal of Medical Sciences, 36(COVID19-S4), S27-S31. https://doi.org/10.12669/pjms.36.COVID19-S4.2785

Nevid, J. S. (2017). Psikologi Konsepsi dan Aplikasi, terjemahan M. Chozim. In Bandung: Nusa Media (p. 790).

Nguyen, T. (2015). The effectiveness of online learning: Beyond no significant difference and future horizons. MERLOT Journal of Online Learning and Teaching, 11(2), 309-319.

Onyema, E. M., Eucheria, N. C., Obafemi, F. A., Sen, S., Atonye, F. G., Sharma, A., \& Alsayed, A. O. (2020). Impact of Coronavirus pandemic on education. Journal of Education and Practice, 11(13), 108-121.

Otto, B. (2015). Perkembangan bahasa pada anak usia dini. Jakarta: Kencana.

Patton, M. Q. (1990). Qualitative evaluation and research methods. SAGE Publications, inc.

Rasmitadila, Aliyyah, R. R., Rachmadtullah, R., Samsudin, A., Syaodih, E., Nurtanto, M., \& Tambunan, A. R. S. (2020). The perceptions of primary school teachers of online learning during the covid-19 pandemic period: A case study in Indonesia. Journal of Ethnic and Cultural Studies, 7(2), 90-109. https:/ / doi.org/10.29333/ejecs/388

Robbins, S., \& Timothy, A. (2014). Perilaku Organisasi. Salemba Empat.

Ryan, S., Kaufman, J., Greenhouse, J., She, R., \& Shi, J. (2016). The effectiveness of blended online learning courses at the community college level. Community College Journal of Research and Practice, 40(4), 285-298. https://doi.org/10.1080/10668926.2015.1044584

Scagnoli, N. (2009). A review of online learning and its evolution in latin America. Policy Futures in Education, 7(5), 555-565. https://doi.org/10.2304/pfie.2009.7.5.555

Seefeldt, C., Castle, S., \& Falconer, R. C. (2010). Social Studies fot the Preschool/Primary Child. US: Merril.

Siche, R. (2020). What is the impact of COVID-19 disease on agriculture? Scientia Agropecuaria, 11(1), 3-9. https:// doi.org/10.17268/sci.agropecu.2020.01.00

Singh, V., \& Thurman, A. (2019). How Many Ways Can We Define Online Learning? A Systematic Literature Review of Definitions of Online Learning (1988-2018). American $\begin{array}{llll}\text { Journal of } & \text { Distance 289-306. }\end{array}$ https:// doi.org/10.1080/08923647.2019.1663082

Susanto, A. (2017). Pendidikan Anak Usia Dini (Konsep dan Teori). Bumi Aksara.

UNESCO. (2020). COVID-19 Impact on Education. UNESCO Institute for Statistics Data, 19(2), Home. https://en.unesco.org/covid19/educationresponse/

Widodo, H. P. (2014). Methodological Considerations in Interview Data Transcription. International Journal of Innovation in English Language, 3(1), 101-107.

World Health Organization. (2020). General's Opening Remarks at the Media Briefing on COVID-19-11 March 2020. World Health Organization; Geneva, Switzerland. https://www.who.int/director-general/speeches/detail/who-director-general-sopening-remarks-at-the-media-briefing-on-covid-19---11-march-2020

Yang, H., \& Ma, J. (2020). How an Epidemic Outbreak Impacts Happiness: Factors that Worsen (vs. Protect) Emotional Well-being during the Coronavirus Pandemic. Psychiatry Research, 289, 113045. https://doi.org/10.1016/j.psychres.2020.113045 